\title{
Measurement and Analysis of Infrasound Signals Generated by Operation of High-Power Wind Turbines
}

\author{
Tomasz Malec ${ }^{1}$, Tomasz Boczar ${ }^{2}$, Daria Wotzka ${ }^{2} \mathbb{D}$ and Michał Kozioł ${ }^{2, *} \mathbb{( 1 )}$ \\ 1 KFB Acoustics Sp. Z o.o., 51-502 Wrocław, Poland; t.malec@kfb-acoustics.com \\ 2 Faculty of Electrical Engineering Automatic Control and Informatics, Opole University of Technology, \\ 45-758 Opole, Poland; t.boczar@po.edu.pl (T.B.); d.wotzka@po.edu.pl (D.W.) \\ * Correspondence: m.koziol@po.edu.pl
}

Citation: Malec, T.; Boczar, T.; Wotzka, D.; Kozioł, M. Measurement and Analysis of Infrasound Signals Generated by Operation of High-Power Wind Turbines. Energies 2021, 14, 6544. https://doi.org/10.3390/en14206544

Academic Editor: Frede Blaabjerg

Received: 27 August 2021

Accepted: 9 October 2021

Published: 12 October 2021

Publisher's Note: MDPI stays neutral with regard to jurisdictional claims in published maps and institutional affiliations.

Copyright: (c) 2021 by the authors. Licensee MDPI, Basel, Switzerland. This article is an open access article distributed under the terms and conditions of the Creative Commons Attribution (CC BY) license (https:/ / creativecommons.org/licenses/by/ $4.0 /)$.

\begin{abstract}
The development of wind energy and the increasing number of installed wind turbines make it necessary to assess them in terms of the nuisance of the emitted infrasound noise generated by such devices. The article presents the results of measurements and analyses of infrasound emitted during the operation of wind turbines installed in various locations in Poland. Comparative analysis of noise levels in the infrasound and audible range has shown that acoustic energy is mainly in the low and infrasound frequency range, and the measured levels depend significantly on the weighting curves used. On the basis of the results, it was confirmed that the sound pressure level of infrasound signals emitted by the operation of high-power wind turbines, regardless of wind velocity, weather conditions, design solutions of turbines, operating time, rated capacity, does not exceed the criteria specified in the applicable legislation dealing with the assessment of infrasound noise on the working environment.
\end{abstract}

Keywords: infrasound signals; low frequency signals; wind turbine; signal analysis

\section{Introduction}

Nowadays wind energy forms one of the principal renewable sources of electricity generation, in which the kinetic energy of wind is utilized to power turbines. Its source originates from solar energy, which by heating the Earth's surface and creating temperature gradients leads to convection currents in the atmosphere, and differential pressure results in air circulation. The dynamic development of wind energy has taken place continuously over two decades. The number of operating wind turbines has increased along with the installed capacity. Consequently, wind power makes up significant proportion of the overall energy balance of virtually all EU countries, the USA, China and Japan. This leads to a greater interest among local communities, ecological circles, as well as authorities in the strict determination with regard to the potential impact of wind turbine noise on the natural environment, including the conditions described as the acoustic climate. Infrasound noise generated by modern high-power wind turbines is an issue often raised by various bodies designed to assess their potential effect and impact on the environment. At the same time, the opinions and views expressed in this respect are often extremely divergent, which may result from the complexity of the issues raised and the variety of analyzed phenomena. The problems of infrasound noise generated by wind turbines, methods of its measurement and assessment of environmental nuisance involve such issues that require detailed analysis and determination of a reference methodology for purposes of such analysis. It should be emphasized that the level of knowledge on each aspect of the assessment of infrasound noise emitted by wind power installations is quite varied. There are theoretical studies focusing on the methods of generating acoustic waves by rotor blades, as well as by individual devices working in the turbine nacelle and its propagation in an open space [1]. Besides, the methods of testing noise in the audible band have been developed, which are defined in small details, standardized and applied at the modeling stage and during 
recordings in real conditions, which allow the extension of the measurements to include the infrasound bandwidth [2-6]. The nuisance related to infrasound noise is assessed in the working environment. There is no comprehensive nor systematic approach to this issue in the literature, which would include an unambiguous specification of the methods and methodology of measurements, as well as an comprehensive definition of the criterion values on the basis of which it would be possible to objectively assess their potential impact, along with the presentation of typical spectra of infrasound noise emission levels related to the operation of wind turbines.

Infrasound signals are formed by sound (acoustic) waves that originate as a result of mechanical vibrations of molecules in an elastic gas, liquid, or solid. The source of these vibrations is related to the mechanical movement (e.g., of a membrane), which leads to imbalance of the particles present in the environment. Physically, infrasound ("subsonic waves") are acoustic waves whose frequency band is below the hearing threshold of the human ear. It should be noted, however, that at sufficiently high pressure levels infrasound can be perceived both by the ear and by the vestibular system. In fact, human hearing does not stop at $20 \mathrm{~Hz}$, but the perception of pitch is lost and sensitivity lowers as the frequency drops. According to various sources, the range of infrasound frequencies is from 0.1 to $20 \mathrm{~Hz}$ and also includes audible low frequencies [7-12].

The manners applied for describing the phenomena of generation and propagation of infrasound signals are the same as for audible or ultrasonic signals. Infrasound noise is the noise with spectra of components with frequencies from 2 to $20 \mathrm{~Hz}$ (below the range perceived auditory by humans in the classical sense). This range results from the research record concerned with the sensitivity of the hearing organ and results mainly from their inaudibility. Along with the technological development and improvement of measurement tools as well as the use of modern methods of signal processing and analysis [13], the issue of the definition of infrasound frequency ranges has been described in detail in the applicable standards. According to the standards: ISO 7196:1995 [14], ISO 9612:1997 [15] and PN-Z-01338:2010 [16] (Polish standard), it is specified to include the range between 1 and $20 \mathrm{~Hz}$.

In addition to infrasound noise, the notion of low-frequency noise is often applied in the literature in this area, and the frequency bandwidth is extended to include the lower audible frequency range. For the purposes of technical analyses of low-frequency noise, the range is from $10 \mathrm{~Hz}$ to $200 \mathrm{~Hz}$, while according to PN EN 61400-11 [17], the range is from $20 \mathrm{~Hz}$ to $100 \mathrm{~Hz}$, respectively. We should note at this point that the infrasound and low-frequency ranges often superimpose in a smooth manner (as they overlap with each other), which consequently requires the analysis of infrasound signals, taking into account the influence of higher frequencies, in the low-frequency range.

Infrasound noise affects the ear, internal organs, respiratory, nervous and vasopulmonary systems. It is perceived in the body through a specific auditory pathway (mainly by the ear), and beyond by vibration sensing receptors, especially in muscles, tendons and joints, and directly on the skin. The thresholds of this perception are approximately $(20 \div 30)$ dB higher than the audible range, i.e., hearing thresholds (the value of the acoustic pressure at which hearing of sounds begins). Their audibility is relative primarily to the sound pressure level and the duration of the exposure time. Therefore, the higher the sound pressure level and the longer exposure time to noise, including infrasound, the greater the adverse effect. The history of research and a detailed description of possible effects of infrasound on humans have been widely described, among at work [18-21].

\section{Aims and Scope of Research Works}

As part of the research, measurements of infrasound noise under normal operating conditions of wind turbines were carried out, followed by the analysis of recorded signals involving a variety of alternatives. Their aim was to systematize the state of knowledge and to develop a compact study dealing with the problem of infrasound noise related 
to high-power wind turbines in an orderly and comprehensive manner on the basis of original research and information disseminated in scientific papers.

Throughout the research, the level of infrasound emitted by wind turbines was assessed in the conditions characterized by a variety of parameters and external factors, the measured values were compared to criteria values and guidelines developed with regard to a reference measurement methodology.

\section{Methodology of Measurements and the Test Objects}

3.1. Methodology and Components of the Measuring System

The selection of the methodology of registration, analysis and assessment as well as the adequate selection of measurement spots determines the quality of the obtained results and the possibility of repeating them and, consequently, the possibility of verifying measurements by other interested researchers. In the case of infrasounds, the selection of methodology is of particular importance. Due to the presence of a large number of natural and artificial sources of various origin and poor damping during their propagation, it is necessary to select a method that can offer the detection of infrasound generated by the operation of the turbine in the conditions when the effect of other sources is limited (mainly wind gusts and traffic sources). It seems reasonable to get as close as possible to the source of the signal in order to examine waves with a sufficiently large distance between the measured values of the tested signal and the background noise level. On the other hand, in order to eliminate reflections and limit the effect of wind gusts, it seems sensible to locate the microphone directly on the ground and to use appropriate windshields. When the assessment is performed, an important issue is associated with the need to adequately take into account the weather conditions and operating parameters of the wind turbine throughout the measurements [3,22-25].

The outline of the assumptions is contained in the standard in [17], and it is applied to assess noise generated by wind turbines in the audible band. This standard is utilized to determine the sound level of wind turbines for various wind velocities on the basis of registered variations in the sound pressure level (in practice generally conducted in the range from 5 to $10 \mathrm{~m} / \mathrm{s}$ ). According to the standard, measurements are performed on the ground, while the microphone is located behind the turbine, on a reflecting surface with a diameter of one meter, at a distance depending on the height of the tower and the rotor diameter. Additionally, to reduce the influence of sweeping wind, two windscreens are located on the microphone. At the same time, in order to monitor weather conditions, the standard requires that they need to be measured in front of the turbine at a height of $10 \mathrm{~m}$. The ability to perform measurements in accordance with the standard enables the determination of the acoustic power level in the range of audible frequencies (from $50 \mathrm{~Hz}$ to $10,000 \mathrm{~Hz}$ ), taking into account tonality and the direction of the acoustic wave (as an option). The standard defines in detail the requirements for measuring equipment, measurement procedures, methods of analyzing the results, assessing the uncertainty of the obtained results and the recorded data. It should be emphasized that the standard also allows for the extension of the scope of tests to include infrasound, but does not precisely define the method of their measurement.

The methodology of signal measurement and analysis described in the standard was used in the research carried out to assess the level of infrasound emission by high-power wind turbines. When the measuring instruments are arranged in accordance with the provisions of the standard, it is possible to clearly assess the level of infrasound emission. When measurements are performed in accordance with the assumptions of the standard offers the minimization of the effect of sweeping wind, reflections and other sources, which are the main factors that may interfere with recordings.

In the conducted research, emphasis was put on the metering sound pressure level, without converting it into the sound power. This approach was applied to determine the scope of the potential infrasound impact directly at the location of the measurement point. Simultaneously with the measurement of the sound pressure level, measurements of 
wind speed and direction as well as other basic weather parameters were carried out in accordance with the assumptions specified in adequate standards (PN-EN 61400-11:2002, PN-EN 61400-11:2004/A1). In addition, in the case of the potential access to the turbine controller, the electrical parameters of the turbine's operation were also recorded; however, this paper does not contain the results related to electrical parameters of the turbine.

With the purpose of checking the equipment applied in the research, each measurement setup was calibrated prior to and following each measurement by application of a class 1 acoustic calibrator. The test signal was a frequency of $1 \mathrm{kHz}$ with a level of $94 \mathrm{~dB}$.

The measurements carried out in accordance with the standard require that sound is recorded in the conditions of various wind velocities. As the weather conditions during the measurements are stochastic, obtaining the results for the complete spectrum involves the need to perform many hours of recordings. When the measurement times are selected, one should carefully observe the weather forecasts so that as many different wind speeds as possible occur on the day of the recording. This occurs most often during variable weather, when high pressure areas give way to lows. However, rainfall occurs frequently during such shifts, preventing research. Due to all the elements, carrying out measurements for one turbine is a task that requires a lot of preparation and a relatively large number of hours of measurements.

Condenser microphones were applied for recording the variations in the sound pressure level, in which pressure changes lead to the vibrations of the diaphragm. This diaphragm, forming a movable lining of the capacitor, changes the electric capacitance in the time related to pressure changes, and since the microphone is prebiased and both facings are connected to each other with a resistor, proportional changes in voltage can be measured at the microphone output. As the microphone output impedance is low (in the order of several dozen $\Omega$ ), in order to transmit the recorded signals over a longer distance, a microphone preamplifier should be used, the role of which is to increase the impedance. The measuring system used in the study had a very short cable connecting the microphone with the measuring card (total length $3 \mathrm{~m}$ ). However, the measurement card was located directly at the measurement stand with the microphone. Therefore, the possibility of causing interference that could affect the measurement results is negligible or so small that it can be ignored. A digital signal meter with a recording function was used to record the signal measured by the microphone. In the meter, the analog signal by means of analog-to-digital converters (ADC) is sampled and quantized into a digital form, which can be freely processed and analyzed.

Throughout the analysis of digital signals, the most important part of the setup is associated with the analog part. Any interference in the analog part of the measuring setup, after they are converted into digital form, form sources of faulty results and, consequently, may lead to incorrect interpretation of data.

The measuring system included the following elements: a microphone with a preamplifier, a LAN-XI meter, a weather station, an acoustic calibrator. In addition, a windscreen and a round reflecting measuring surface with a diameter of $1 \mathrm{~m}$ were applied in the measurements, which were a set designed and made for noise measurements of wind turbines, in accordance with the [17] standard. An image of the measuring equipment used is presented in Figure 1. Figure 2 shows an example schematic of the measurement system. 


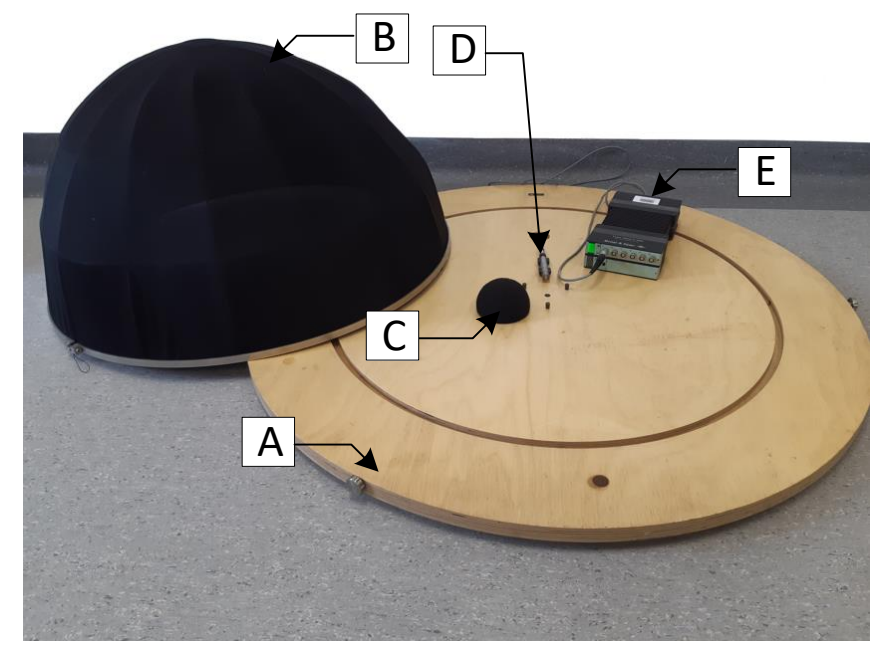

Figure 1. Elements of measuring station: A-reflective board, B-outer wind protection, $\mathrm{C}$-inner wind protection, D-microphone, E-PULSE LAN-XI type 3050-A module.

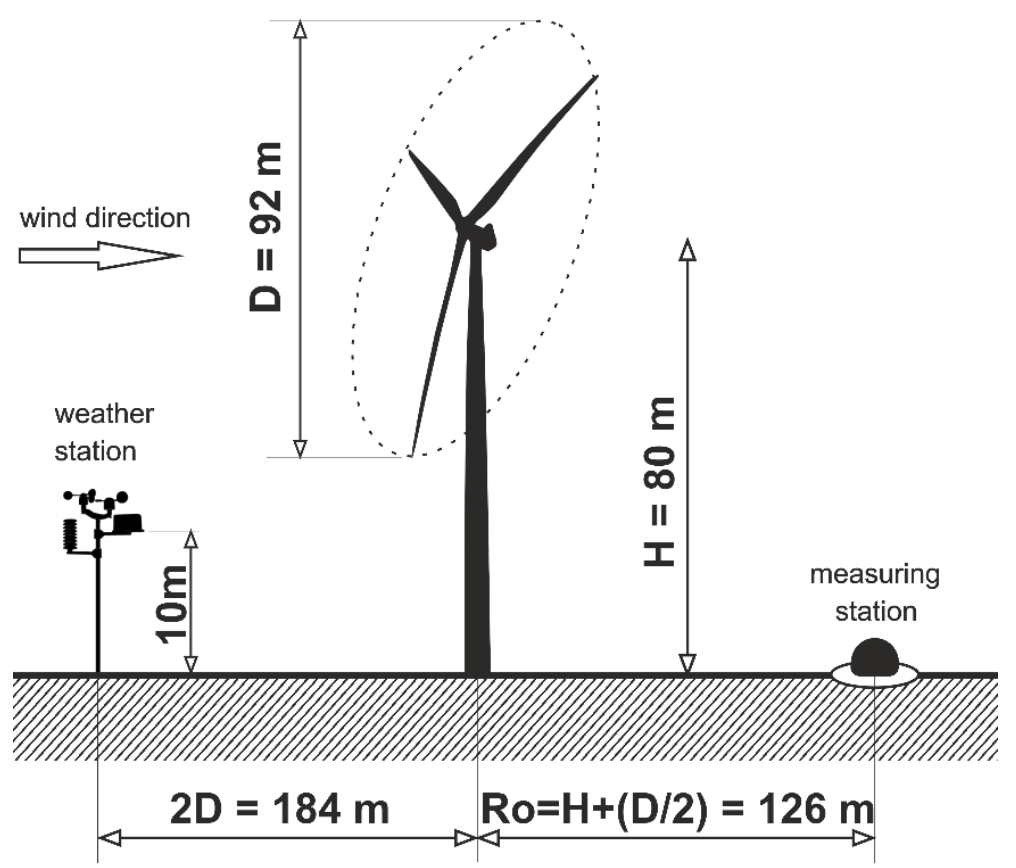

Figure 2. Scheme of the measuring system: example location of the microphone and the meteorological station in relation to the tested wind turbine in accordance with the PN-EN 61400-11 standard.

\subsection{Parameters of Turbines Applied in the Study}

The first tested object involved was a single Vensys type 62 wind turbine with a rated electrical power of 1.2 MW (Figure 3, location 1), adjacent to wind installations of other wind farms, which were located at a distance from $1.2 \mathrm{~km}$ to $2.3 \mathrm{~km}$. The tested turbine has been in operation since 2009. The diameter of the turbine blades is $62 \mathrm{~m}$ and the tower height is $69 \mathrm{~m}$. The neighboring turbines are located to the east. On the day of the measurement the wind was from the west direction. This offered the means to minimize the effect of low-frequency noise emitted by the remaining turbines, as they were located on the leeward side. The tested turbine is located east of the town of Szadek, about $600 \mathrm{~m}$ from built-up areas. Due to the small distances, this environment is a source of a constant background noise level in the infrasound bandwidth.

The second tested facility was a MM92 REPOWER wind turbine with a rated electric capacity of $2 \mathrm{MW}$ (Figure 3, location no. 2), which is part of a newly commissioned wind 
farm consisting of 15 identical turbines, with a total electric power of $30 \mathrm{MW}$. The turbine has been in operation for about one year. The diameter of the turbine blades is $92 \mathrm{~m}$ and the tower height is $80 \mathrm{~m}$. A turbine standing in the axis perpendicular to the wind direction was selected for the tests. In this way, the impact of low-frequency noise emitted by the remaining turbines was minimized. The tested turbine is located east of the town of Lipniki, about $850 \mathrm{~m}$ from the nearest built-up areas. Due to the long distance and small acoustic nuisance, this turbine forms a source of low acoustic background in the infrasound band.

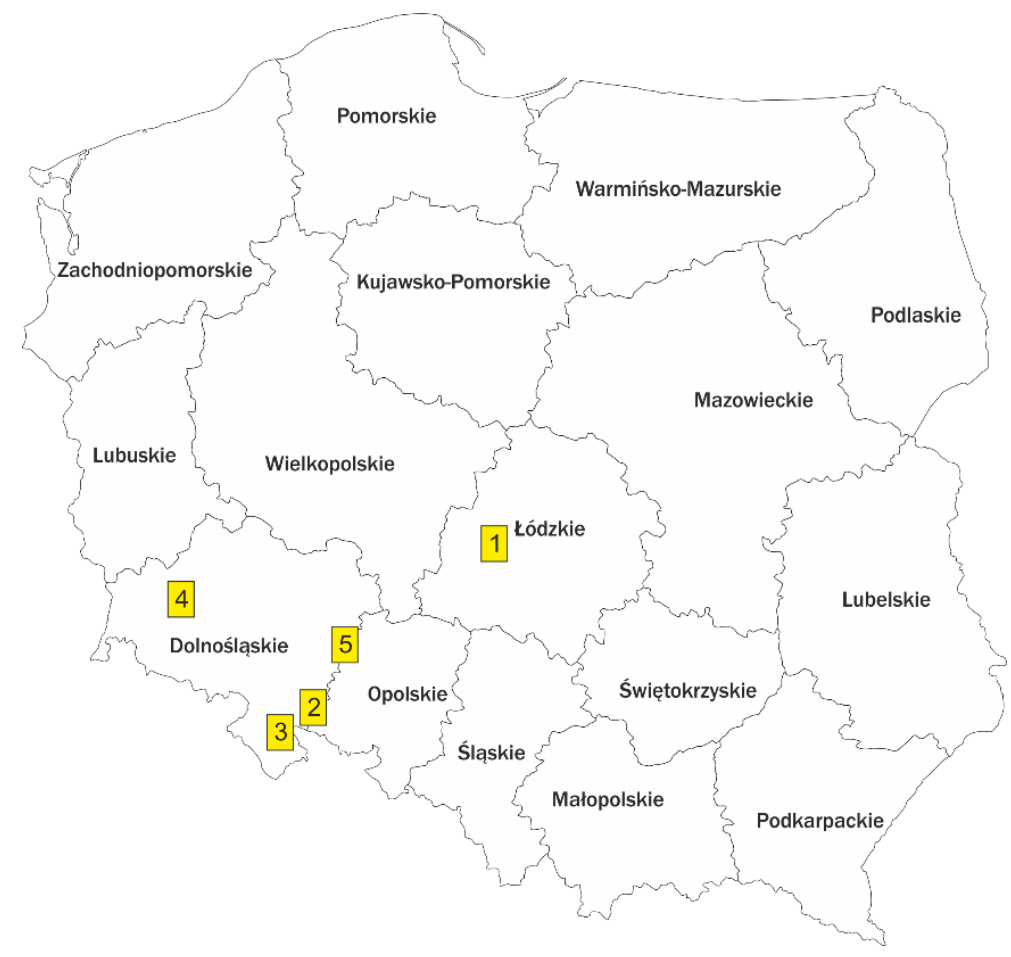

Figure 3. Location of wind turbines under study.

The third tested facility was a single 64 Vensys wind turbine with a rated electrical capacity of 1.2 MW (location no. 3). During the conducted measurements, the tested turbine was a single installation. However, at present, next to the tested turbine, the investor has installed two more turbines. The turbine has been in operation since 2011 . The diameter of the turbine blades is $64 \mathrm{~m}$ and the height of the tower is $85 \mathrm{~m}$. The tested arming was located south of Paczków, approx. $600 \mathrm{~m}$ from the built-up areas of the village of Unikowice. Due to relatively short distances and considerable acoustic nuisance related to the car traffic, the environment forms a source of a constant and high level of acoustic background in the infrasound range.

The fourth tested facility was a REPOWER MM92 wind turbine with a rated electric capacity of 2 MW (location no. 4), which is part of a newly commissioned wind farm consisting of 22 identical turbines, with a total electric power of $45 \mathrm{MW}$. The turbine has been in operation for about three months. The diameter of the turbine blades is $92 \mathrm{~m}$ and the height of its tower is $100 \mathrm{~m}$. A turbine situated in the northern part of the farm was selected for the tests. Several other turbines were operating in its immediate vicinity. In this way, the emission of low-frequency noise emitted against the background of other turbines was determined. The tested turbine is located north of the town of Taczalin, about $1200 \mathrm{~m}$ from built-up areas. Due to the high acoustic nuisance associated with the traffic of cars, the environment is a source of a constant and high level of acoustic background in the infrasound range.

The fifth tested object involved the Vestas V112 wind turbine with an electrical capacity of $3 \mathrm{MW}$ (location no. 5), which is part of a newly commissioned wind farm consisting of 17 identical turbines, with a total electrical power of $51 \mathrm{MW}$. The turbine has been in operation 
for about one year. The diameter of the turbine blades was $112 \mathrm{~m}$, and the tower height was $119 \mathrm{~m}$. A turbine located in the southern part of the farm was selected for the tests. Other wind farms were operating in its vicinity. In this way, the emission of low-frequency noise emitted against the background of other turbines was determined. The tested turbine is located to the south-west of the town of Pagów, about $1600 \mathrm{~m}$ from the nearest built-up areas. The surroundings, due to the low acoustic nuisance and the relatively large distance, are the source of a low level of acoustic background in the infrasound range [7].

\section{Results of Analysis}

In the first stage, the uncertainty of the measurement system was assessed, as this step provides the possibility of determining the quality of the results. During noise measurements, type B uncertainty consists mainly of uncertainties related to calibration and uncertainties resulting from the accuracy class of the measuring instrument. The uncertainty of the applied B-type measurement system was 0.43 , while the expanded uncertainty of B-type was $0.86 \%$ with the confidence range equal to $95 \%$.

The sound pressure level was applied without the use of G-weighting curves for the purposes of assessing infrasound noise emission during the operation of high power wind turbines. For a detailed analysis, it is reasonable to present the results in the function of frequency, so that it is possible to perform an accurate evaluation of the recorded signals. Additionally, in order to determine the nuisance for humans of the tested signals and to indicate differences with regard to the registered relations, it was necessary to present the results following weighing by application of appropriate weighing curves.

In order to define a single-number rating representing noise exposure, describing the effects corresponding to the measurement time, the concept of the equivalent noise level was introduced, which is described by the relation (1):

$$
L_{e q}=10 \times \log \left(\frac{1}{T} \int_{0}^{T} \frac{p^{2}(t)}{p_{0}^{2}} d t\right) .
$$

where:

$T$-measurement time (s), $p$-registered variations in acoustic pressure $(\mathrm{Pa})$, $p_{0}$-reference pressure $\left(2 \times 10^{-5} \mathrm{~Pa}\right.$-hearing threshold for $\left.1 \mathrm{kHz}\right)$

\subsection{Application of Weighting Curves}

In order to relate the measured values to the human perception of noise, it was necessary to use weighing filters. In the range of audible frequencies, $\mathrm{A}$ and $\mathrm{C}$ weighting curves are most often employed. However, in order to assess the influence of sounds in the infrasound range, a $\mathrm{G}$ weighting curve is used [26].

The results of the application of $A, C$ and $G$ weighing curves and the course of the input spectrum without weighing, obtained during measurements of changes in the sound pressure level in the band from 1 to $200 \mathrm{~Hz}$, are shown in Figures 4-8-for locations 1-5, respectively. The analysis of the obtained results also revealed some dominant frequency components (occurring in the frequency range from $12 \mathrm{~Hz}$ to $20 \mathrm{~Hz}$ ) which may be related to the rotation of the wind turbine blades. This issue requires further research, which is beyond the scope of this article. 


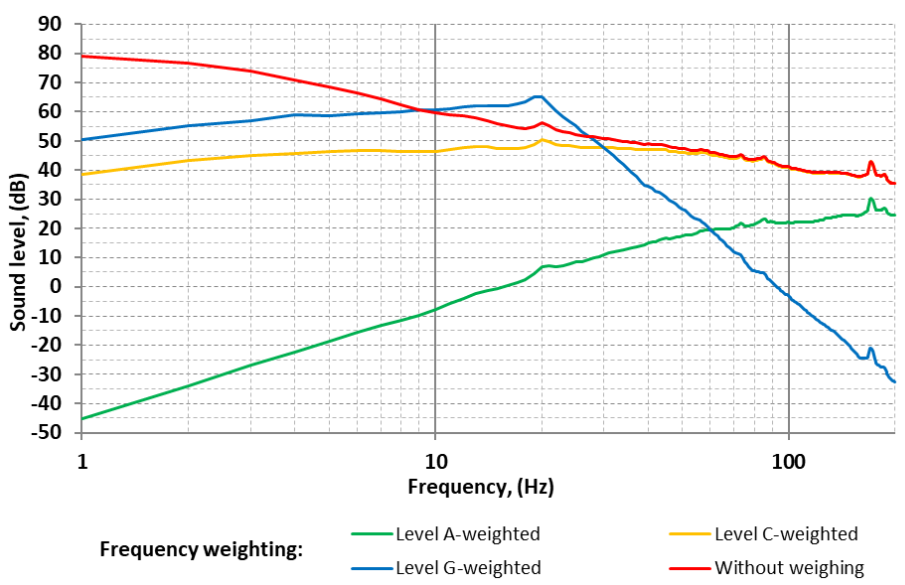

Figure 4. Courses of noise spectra generated by T1 turbine by application of various weighting curves.

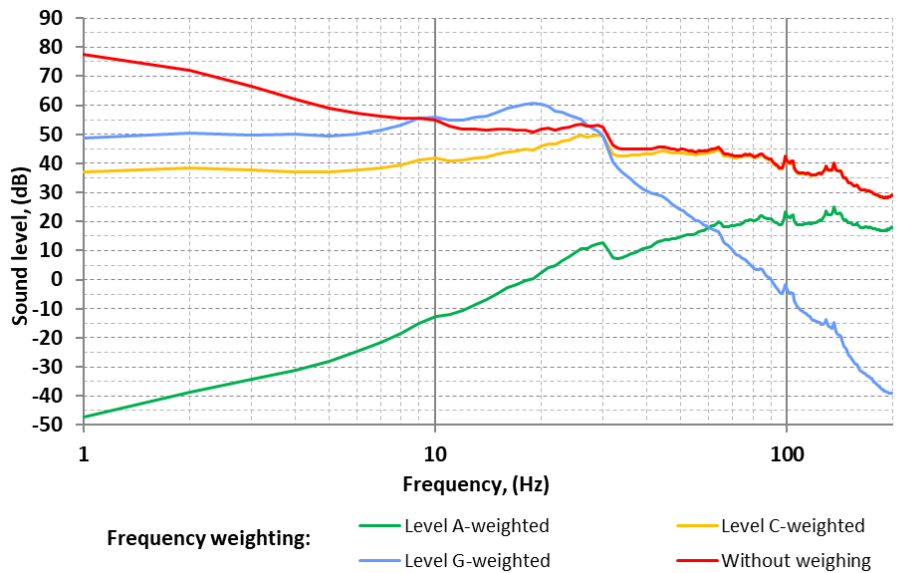

Figure 5. Courses of noise spectra generated by T2 turbine by application of various weighting curves.

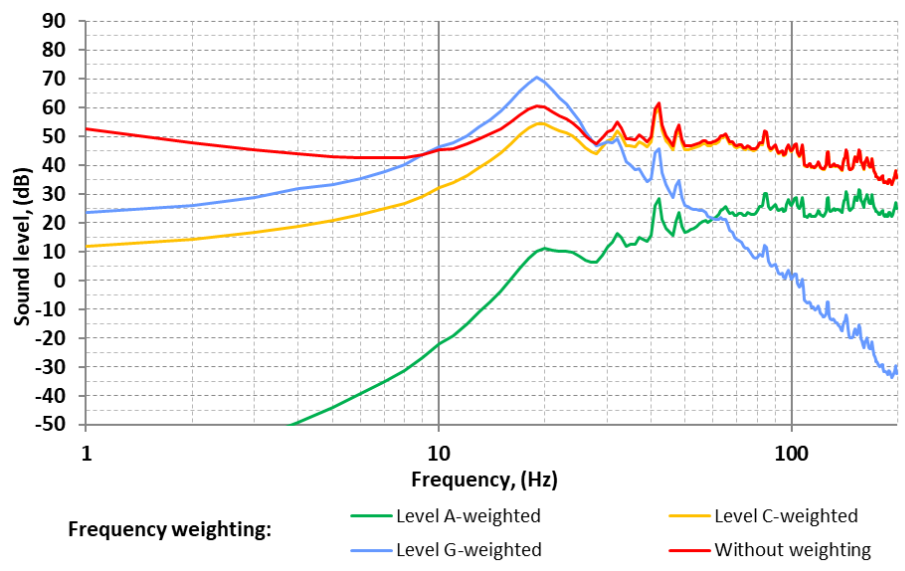

Figure 6. Courses of noise spectra generated by T3 turbine by application of various weighting curves. 


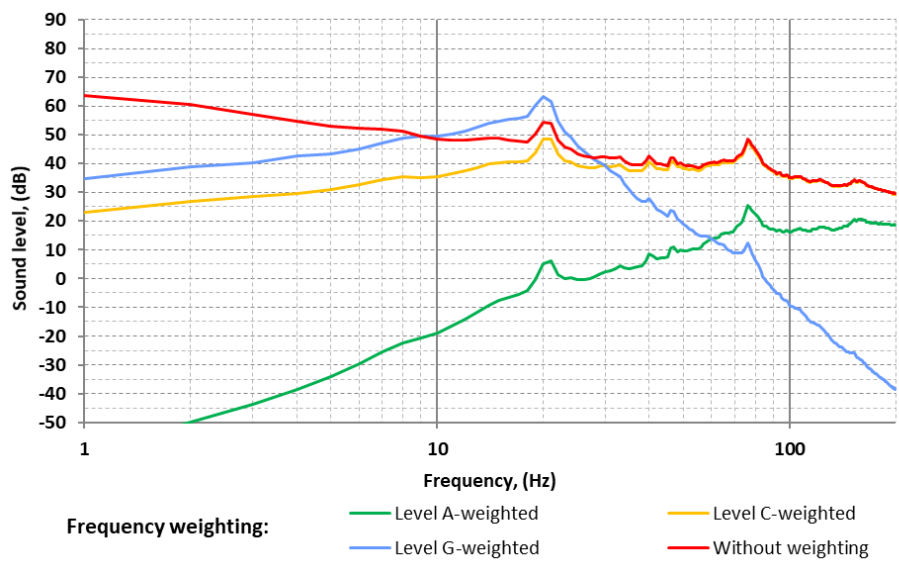

Figure 7. Courses of noise spectra generated by T4 turbine by application of various weighting curves.

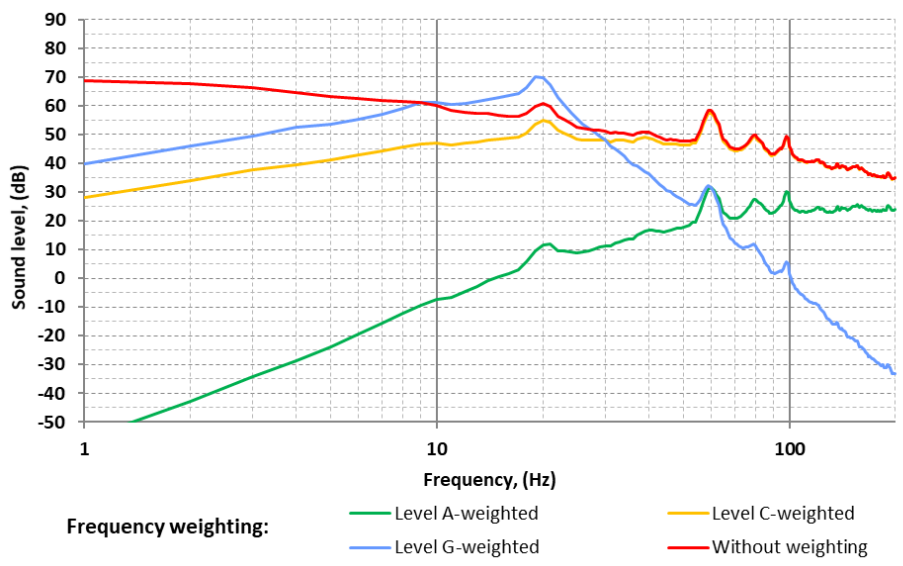

Figure 8. Courses of noise spectra generated by T5 turbine by application of various weighting curves.

\subsubsection{Discussion of the Results for T1}

The use of weighting curves significantly alters the image representing the impact of the investigated wind turbines. The equivalent noise level, formed by the total of the noise levels recorded for individual curves in the range from 1 to $200 \mathrm{~Hz}$, and constituting a single-value representation of the results presented above, assumes the following values:

- Noise level without weighting (FFT) - 85.4 dB;

- Noise level weighted by A curve-45.9 dB;

- Noise level weighted by C curve-66.7 dB;

- Noise level weighted by G curve-75.0 dB.

The weighting curves $\mathrm{A}$ and $\mathrm{C}$, developed for the assessment of noise in the audible band below $60 \mathrm{~Hz}$ for curve $\mathrm{C}$ and over the entire analyzed band for curve $\mathrm{A}$, successfully damp the signal measurement, resulting in significantly lower values of the equivalent noise level, which forms the basis for the assessment its nuisance to humans.

In the case of the tested wind turbine, the key factor that affected the result of the acoustic nuisance assessment using the G-weighting curve was associated with the increase of the sound level around $20 \mathrm{~Hz}$.

\subsubsection{Discussion of the Results for $\mathrm{T} 2$}

The equivalent noise level formed by the sum of the noise levels for individual curves in the band from 1 to $200 \mathrm{~Hz}$, constituting a single-value interpretation of the results presented above, assumes the following values:

- Noise level without weighting (FFT) - 82.9 dB;

- $\quad$ Noise level weighted by A curve-41.7 dB; 
- Noise level weighted by C curve-64.3 dB;

- Noise level weighted by G curve-71.1 dB.

For the case of the tested wind turbine, the key factor that affected the result of the assessment of its acoustic nuisance with the use of the G-weighting curve was associated with the stabilization of the noise level above $10 \mathrm{~Hz}$ combined with the increase of the sound level in the band from 20 to $30 \mathrm{~Hz}$.

\subsubsection{Discussion of the Results for T3}

The equivalent noise level, being the sum of the noise level for individual curves in the band from 1 to $200 \mathrm{~Hz}$, constituting a single-value interpretation of the results presented above, assumes the following values:

- Noise level without weighting (FFT) - $72.3 \mathrm{~dB}$;

- Noise level weighted by A curve-47.5 dB;

- Noise level weighted by C curve-69.3 dB;

- Noise level weighted by G curve-76.3 dB.

For the case of this installation, the effects of noise sources other than the turbine are clearly perceptible. After applying the A-weighting curve, unlike for the previously analyzed generators, the noise level does not decrease rapidly with the drop in frequency. The value of the sound level weighted by the weighting curve $C$ is determined by components above $30 \mathrm{~Hz}$. All these factors mean that despite a very small share in the measured noise levels from the tested wind turbine, the equivalent noise levels weighted by various curves remain at relatively high levels.

\subsubsection{Discussion of the Results for T4}

The equivalent noise level formed by the sum of the noise levels for individual curves in the band from 1 to $200 \mathrm{~Hz}$, constituting a single-value interpretation of the results presented above, assumes the following values:

- Noise level without weighting (FFT) -70.0 dB;

- Noise level weighted by A curve-40.4 dB;

- Noise level weighted by C curve-61.2 dB;

- Noise level weighted by G curve-78.9 dB.

In the case of the tested wind turbine, the key factor affecting the result of the acoustic nuisance assessment using the G-weighting curve is associated with the increase of the sound level around of $20 \mathrm{~Hz}$.

\subsubsection{Discussion of the Results for $\mathrm{T} 5$}

The equivalent noise level formed by the sum of the noise levels for individual curves in the band from 1 to $200 \mathrm{~Hz}$, constituting a single-value interpretation of the results presented above, assumes the following values:

- Noise level without weighting (FFT) - 77.4 dB;

- Noise level weighted by A curve-46.6 dB;

- Noise level weighted by C curve-69.4 dB;

- Noise level weighted by G curve-77.0 dB.

In the case of the tested wind turbine, the key factor affecting the result of the acoustic nuisance assessment using the G-weighting curve is associated with the increase of the sound level around of $20 \mathrm{~Hz}$.

In order to perform a comparative analysis of the obtained relations, the equivalent sound levels calculated for the entire bandwidth taken in the analysis $(1-200 \mathrm{~Hz})$ were subsequently compiled, by application of weighting curves as well as in the conditions when weighting curves are not used. The calculated values of the equivalent sound level, which were determined separately for the analyzed wind turbines, are presented in Figure 9. The use of the A-weighting curve cuts off the spectrum in the low and infrasound frequency ranges and leads to the decrease of the impact of the wind turbines noise. When 
the use of weighting is shifted to the use of C curve, the low frequency range is not cut off, but the infrasound components are eliminated. The $\mathrm{G}$ weighting curve is utilized in the assessment of the impact of infrasound components on humans.

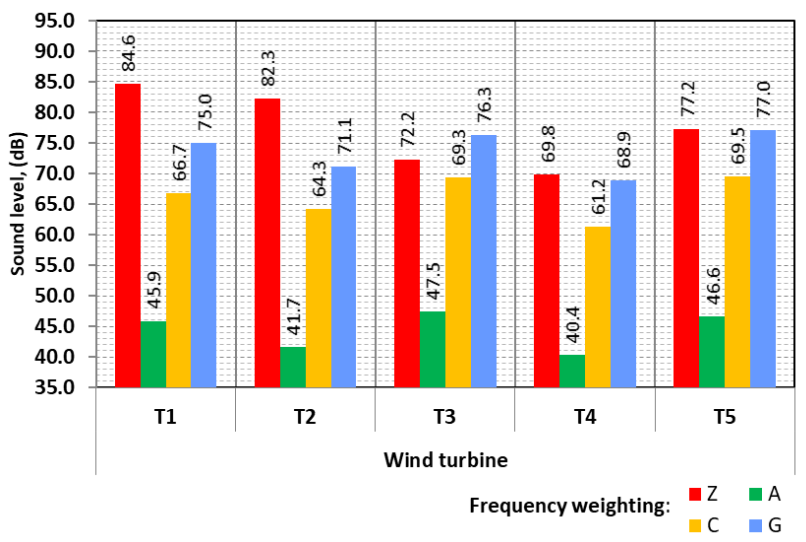

Figure 9. Comparison of the values of equivalent noise levels of investigated turbines for various weighting curves as well as excluding weighting.

\subsection{Determination of the Effect of Wind Speed on the Sound Pressure Level of Infrasound}

The main parameter that determines the level of acoustic power of wind turbines is related to velocity of the wind that drives its rotor. This speed determines the number of rotor revolutions and thus the electricity production by the generator. Additionally, depending on the wind speed, the automatic control of the turbine sets the appropriate rotor blades angle of attack and the optimal angle of rotation of the nacelle. All these wind turbine parameters affect the noise level and its spectrum, both in the infrasound and audible band. The greatest variability of the wind speed was recorded during the measurements performed at the T1 turbine in location 1 and, respectively, at T2 in location 2, and the range of recorded variations was:

- For T1: $\max =9.8 \mathrm{~m} / \mathrm{s}, \min =3.6 \mathrm{~m} / \mathrm{s}$;

- For T2: $\max =7.6 \mathrm{~m} / \mathrm{s}, \min =1.3 \mathrm{~m} / \mathrm{s}$.

The range of the variations in wind speed throughout the measurement made it possible to register changes in the sound level in the infrasound band in practically the entire range of turbine performance. The wind turbines start up occurs for the wind speeds of $3 \mathrm{~m} / \mathrm{s}$. On the other hand, at wind speeds of $(8-12) \mathrm{m} / \mathrm{s}$, depending on the design solutions used, they achieve $100 \%$ of rated capacity, which is maintained up to the speed of about $23-25 \mathrm{~m} / \mathrm{s}$, at which the turbine is automatically stalled. In the example of T1 and T2 turbines, the influence of wind speed on the sound pressure level of generated infrasound was analyzed. The scope of performed measurements and analysis included the determination of waveforms containing details of the variations in the sound pressure level in the function of frequency (amplitude spectra) and in the time-frequency domain (spectrograms), without the use of weighting curves.

For the case of the T1 turbine, the spectrum of noise in the infrasound band does not affect changes in the course of the waveform and does not depend on the wind speed to a considerable extent. After the turbine is turned on, at a wind speed above $3 \mathrm{~m} / \mathrm{s}$, the noise level remains virtually constant, and slightly lower values are only reached for the lowest recorded wind speed. The highest values, in the order of $80 \mathrm{~dB}$, can be observed for the lowest frequencies, in the range of several hertz. As the frequency increases, the noise level initially decreases rapidly to about $50 \mathrm{~dB}$ at $30 \mathrm{~Hz}$. However, above this frequency, the dynamic characteristics of noise variations significantly falls, and the noise level further decreases, reaching the value of about $35 \mathrm{~dB}$ at the frequency of $200 \mathrm{~Hz}$. This is confirmed by the range of changes in the equivalent noise level, being the sum of the noise level for individual spectra, constituting a single-value representation of the results, which are summarized in the diagram presented in Figure 10. 


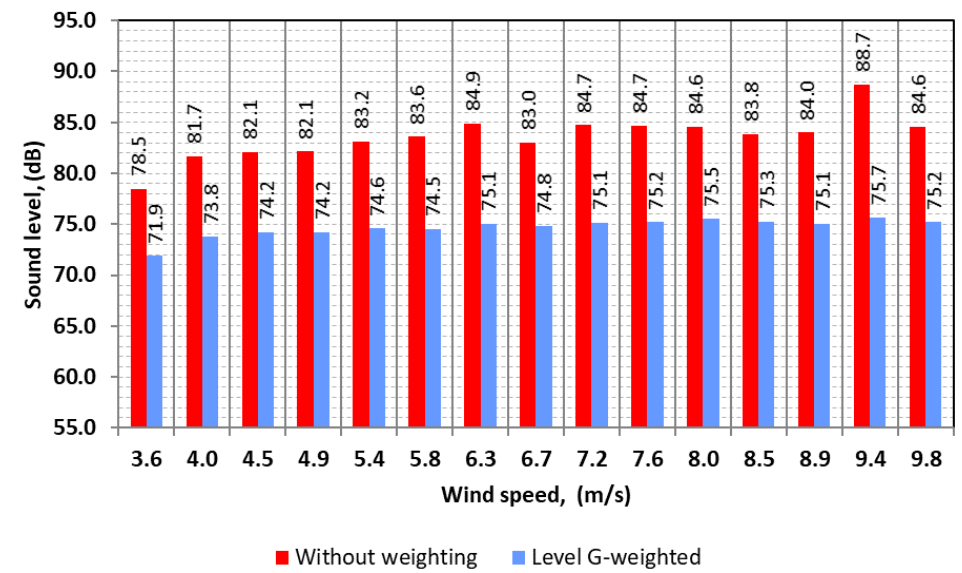

Figure 10. Comparison of variations in noise levels in the function of wind speeds-T1 turbine.

Apart from the above dependencies, just as in the case of the analysis of changes in the total noise level, in the recorded spectra there are two tonal frequencies for which an increase in the pressure level was recorded.

In the case of the $\mathrm{T} 2$ turbine, the influence of the wind velocity on the noise emission spectrum in the infrasound and low-frequency bands is significant, and the dynamics of the variations assumes $15 \mathrm{~dB}$. The highest noise levels correspond to the greatest wind speeds. As the wind speed decreased, the sound level generated by the tested turbine decreased. The highest values occur in the infrasound band from 1 to $30 \mathrm{~Hz}$. At low wind speeds, within the range of (1-3) $\mathrm{m} / \mathrm{s}$ at which the rotating nacelle with the rotor searches for optimal wind conditions, the noise spectrum assumes the lowest levels. However, as the frequency value increases, the noise level decreases in a linear manner. In the determined spectrum, we can also distinguish several harmonic components that significantly differ from the adjacent components. The first one with the highest level is in the 10 to $30 \mathrm{~Hz}$ bandwidth. It correlates well with the wind velocity. For low wind velocities, the maximum sound pressure level is close to $10 \mathrm{~Hz}$. As the wind velocity increases, this maximum shifts towards higher frequencies and the highest frequency (about $30 \mathrm{~Hz}$ ) is recorded for wind velocity of $7.6 \mathrm{~m} / \mathrm{s}$. The confirmation of the effect of wind velocity on the measured noise level is given by the range of variations in the equivalent noise level illustrated in Figure 11.

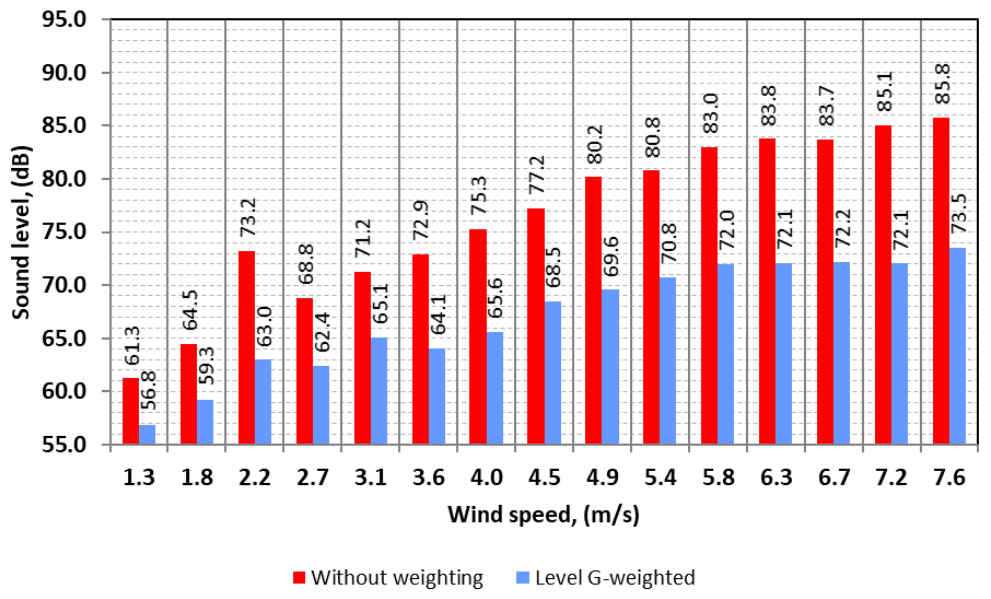

Figure 11. Comparison of variations in noise levels in the function of wind speeds-T2 turbine.

On the basis of the analysis of signal dynamic characteristics, we can note that, as with changes in the general noise level, its highest levels are recorded in the range of single hertz, and with increasing frequency these levels gradually decrease in value, reaching higher values only in the region of tonal frequencies. 


\subsection{Determination of the Effect of Temperature and Humidity on Acoustic Pressure Levels of Generated Infrasound}

The greatest variability of temperature and humidity was recorded during the measurements made at $\mathrm{T} 2$ for location $2: \max =24.8^{\circ} \mathrm{C}, \min =17.1^{\circ} \mathrm{C}$. The variations in the humidity levels were in the range from $71 \%$ to $44 \%$, respectively.

During the observed changes in temperature and humidity, the wind speed also varied; therefore, the determination of the effect of the analyzed weather parameters on the variations in the noise level in the infrasound range is strongly dependent on the wind conditions prevailing at a given moment. The scope of the performed analyses included the determination of waveforms illustrating changes in the acoustic pressure level as a function of frequency (amplitude spectra) and changes in the equivalent noise level, formed by the total of the noise level for individual spectra, constituting a single-value representation of the results.

The amplitude spectra derived for the tested turbines are presented in Figure 12 (influence of temperature) and in Figure 13 (influence of humidity), respectively, and they are calculated in the same manner as presented before.

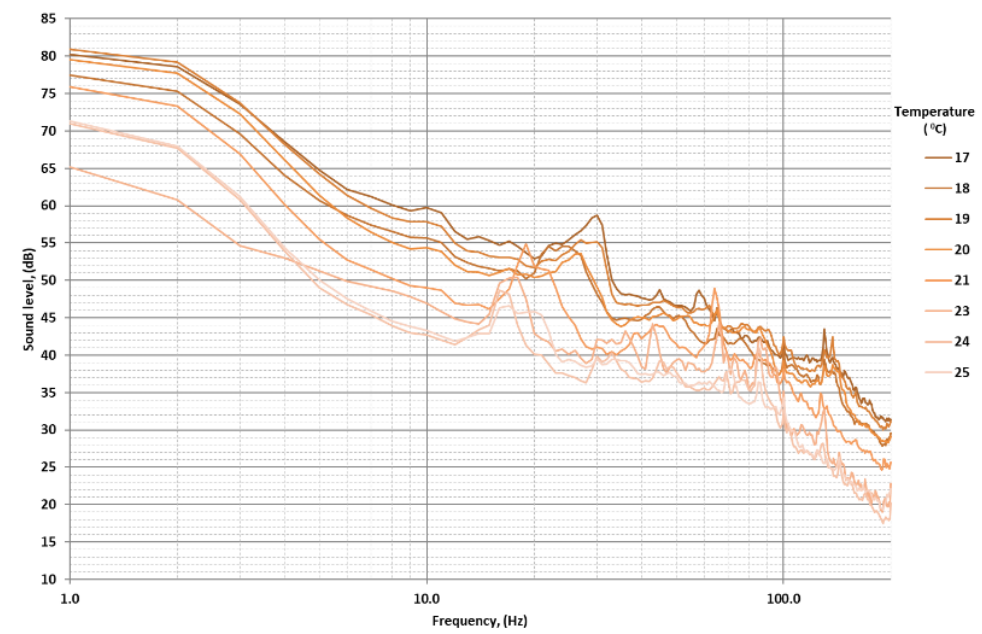

Figure 12. Course of amplitude spectra in the function of frequency for various temperatures-T2 turbine.

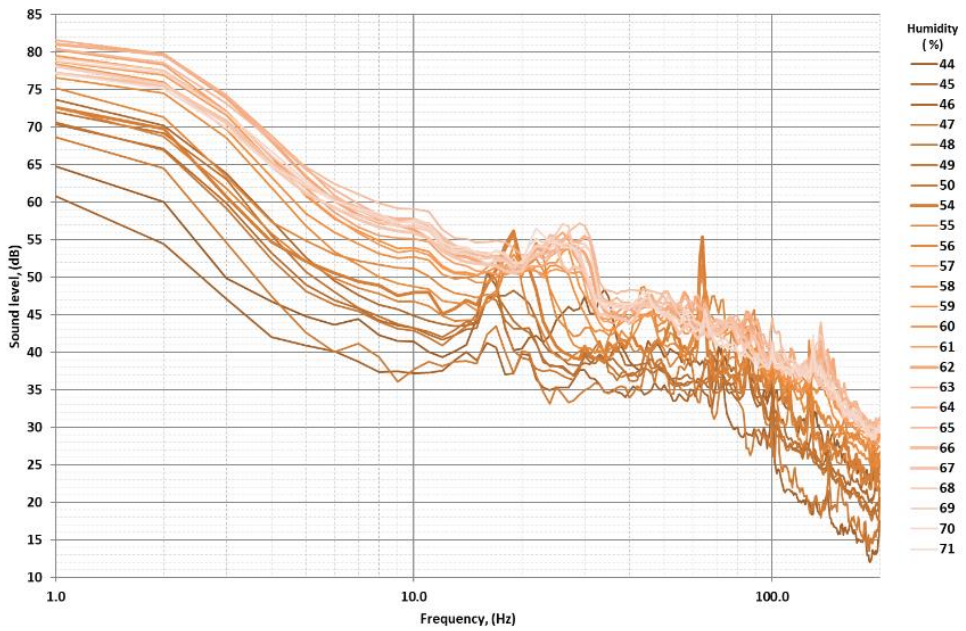

Figure 13. Courses of amplitude spectra representing noise levels in the function of frequency for various air humidity- $\mathrm{T} 2$ turbine.

The variations in the equivalent sound level occurring at the averaged wind speed are presented in Figure 14 (to demonstrate the effect of the temperature) and Figure 15 (to demonstrate the effects of the humidity). 
The range of the variations in the noise spectrum at different temperatures is similar to the one that was observed with the changes in the wind and results mainly from the mean wind velocities occurring during the experimental part of the study. The highest values of the sound level accompany the range of the lower frequencies and lower temperatures. As the frequency and temperature increase, the noise level decreases as well. The presence of the increase in the spectrum is also characteristic, in the bandwidth from 10 to $30 \mathrm{~Hz}$, and shifts towards lower frequencies as the temperatures increase. The effect of temperature on the acoustic emission can be seen in detail in the bar charts in Figure 14.

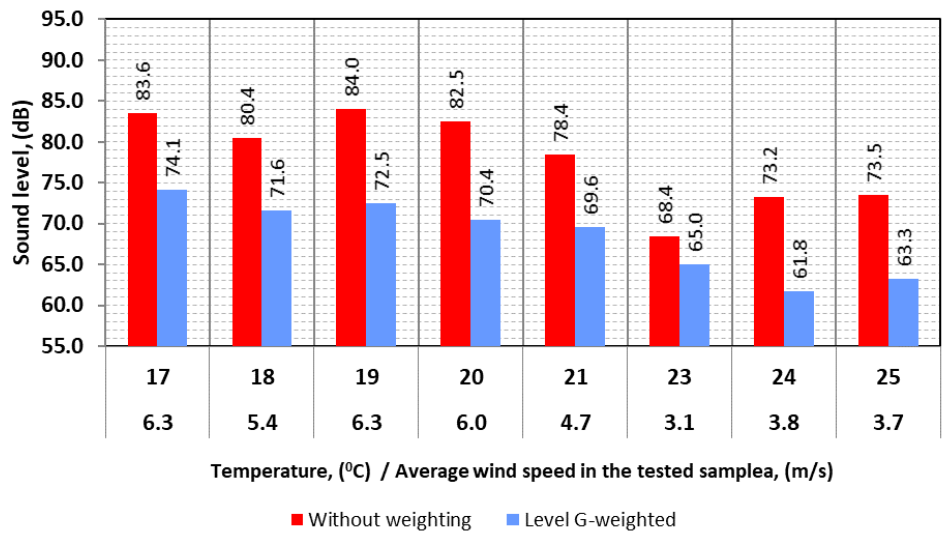

Figure 14. Variations in noise level in the function of temperature- $\mathrm{T} 2$ turbine.

On the measurement day, the mean wind speed decreased along with the increase in temperature, which had a direct effect on the results of the experiment. Only for the temperatures $17^{\circ} \mathrm{C}, 19^{\circ} \mathrm{C}$ and $20^{\circ} \mathrm{C}$ was the wind speed similar and it was possible to analyze the influence of temperature changes on the level of noise. For specific temperatures, an increase in their value leads to a decrease in the noise level in the infrasound range.

Similar conditions are recorded in the conditions of varied air humidity. As the insolation increased, the air humidity decreased, the temperature value increased and the wind speed was smaller. All these factors meant that the sound level fell with a decrease in humidity. At relatively constant wind speeds, which remained in the humidity range of 57 to $71 \%$, it can be seen that initially with increasing humidity the sound level decreases to stabilize at a relatively constant level above 65\% humidity (Figure 15).

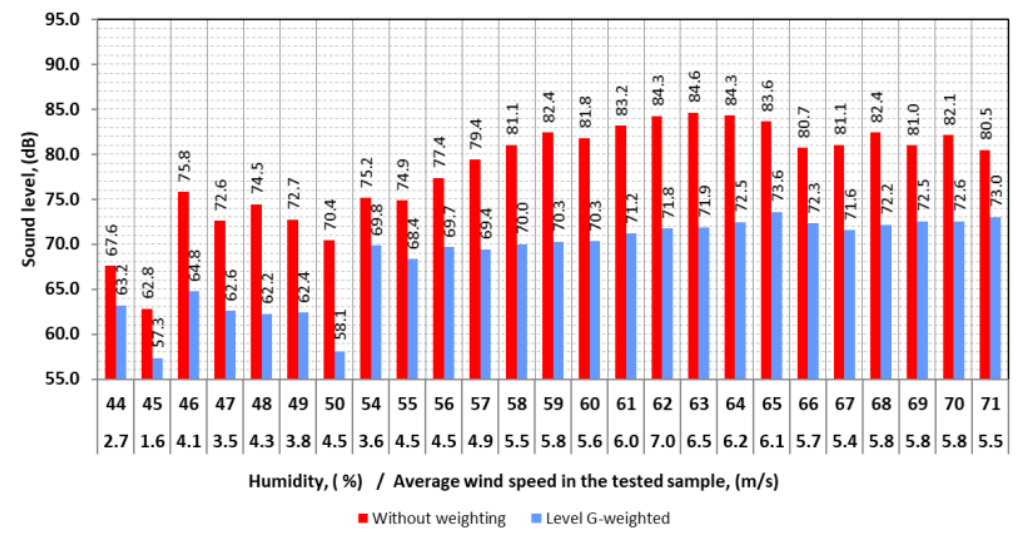

Figure 15. Variations in noise level in the function of air humidity-T2 turbine.

4.4. Assessment of the Effect of the Amount of Electricity Delivered by Wind Turbines to the Power System on the Level of Acoustic Pressure of Infrasound

In order to determine the dependence of the variations in the amount of electric power delivered to the power system on the level of acoustic pressure generated by a wind turbine in the infrasound band, averaged waveforms of amplitude spectra for the 
electric energy values produced by the turbine were developed. It should be noted that the amount of electric power is closely related to the wind speed. This relation is provided by manufacturers in the form of a power curve. Among the tested turbines, access to the information regarding the amount of electric power delivered during the measurements was possible with regard to $\mathrm{T} 1$ turbine. The course of the electric power curve for the tested turbine as declared by the manufacturer is presented in Figure 16.

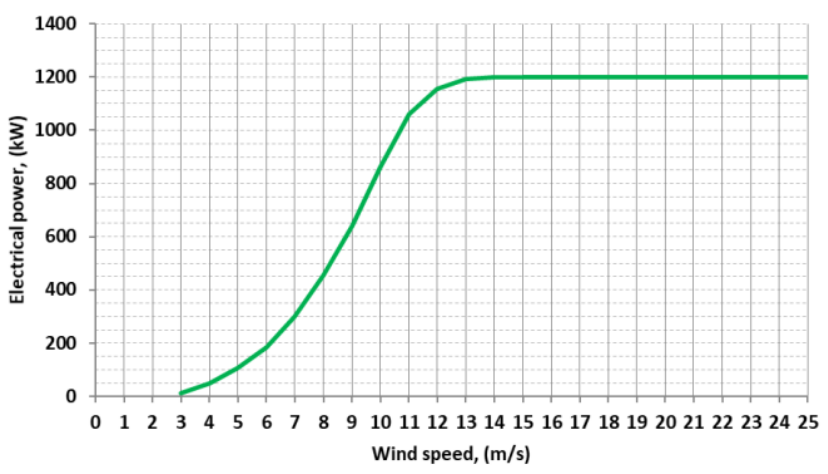

Figure 16. Course of power curve for $\mathrm{T} 1$ turbine-manufacturer data.

Throughout the measurements, the wind speed was subject to large fluctuations in the value ranging from $3.6 \mathrm{~m} / \mathrm{s}$ to $9.8 \mathrm{~m} / \mathrm{s}$, which meant that electric power output varied in the range from $350 \mathrm{~kW}$ to $1150 \mathrm{~kW}$. The recorded range of changes in wind speed provided grounds for the analysis of infrasound generated by the tested turbine in a wide range of operating conditions. The remaining weather parameters and operating conditions remained constant and did not vary significantly throughout the measurements.

The range of variations in the equivalent noise level, formed by the total of the noise level for individual spectra, and being a single-value interpretation of the presented results, is presented in Figure 17.

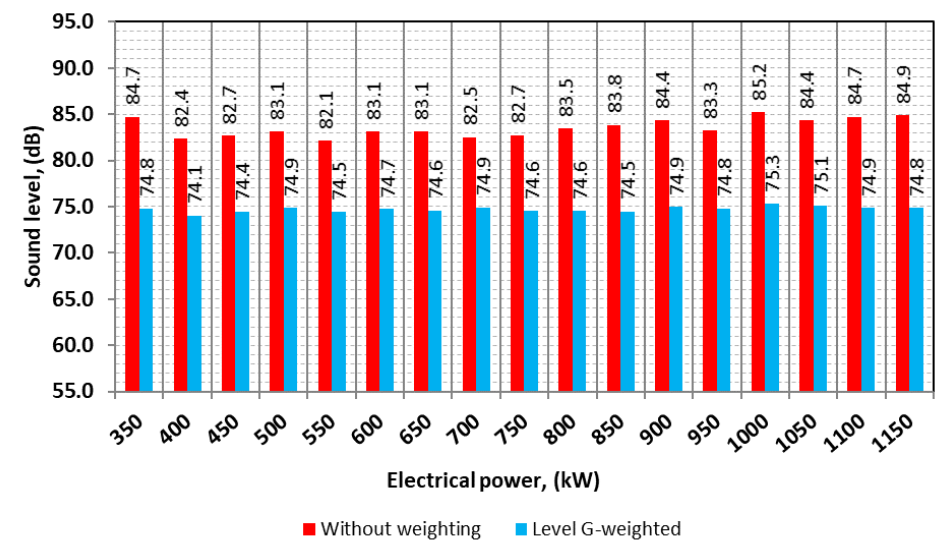

Figure 17. Variations in noise level in the function of volume of electricity delivered to the power system by $\mathrm{T} 1$ turbine.

\subsection{Comparative Analysis of Acoustic Signal in the Infrasound and Audible Range}

In order to perform a comparative analysis of the noise levels recorded in the infrasound and low frequencies with the levels generated in the audible band (from $20 \mathrm{~Hz}$ to $20 \mathrm{kHz}$ ), measurements were conducted for a wider range of frequencies. For this purpose, throughout the measurements carried out for the turbines T2, T3 and T4, signals were additionally recorded in the audible band. This provided the means to determine the time-frequency distributions of the recorded signals and to calculate the equivalent noise levels. 
The summary of single-number sound level values determined for different weighting curves as well as without weighting with regard to infrasound and audible bands is presented in Figure 18. From the presented graphs, we can see that the sound level without weighting assumes higher values in the low and infrasound frequency bands for all three turbines. This demonstrates the presence of the highest signal energy in these ranges, which is due to relatively poor damping of these components by the propagating environment. The differences between the results of weighted curves $A$ and $C$ result only from the presence of significant background components in the audible band and the operation of the turbine itself. Weighting the measurement results with the G-curve clearly filters the higher spectrum components and offers the limitation of the scope of the analysis to infrasound components only, which makes the subsequent interpretation of the results easier. The difference between the $\mathrm{A}$ and $\mathrm{C}$ weighting curves in this range can be utilized to evaluate the noise in the low frequency range from 20 to $200 \mathrm{~Hz}$. The smaller the difference between the A and C level-weighted curves, the fewer low-frequency components there are in the tested signal. The differences in the analyzed spectra are significant; therefore the occurrence of low-frequency components in the investigated signals can be confirmed.

Currently, on the basis of the available measuring devices and systems, it is possible to determine the precise location of the acoustic wave emission directly on the operating wind turbine. For this purpose, measurements are performed by application of state-of-the-art acoustic cameras. An acoustic camera is a set of microphones coupled to an optical camera. As a result, it is possible to indicate the directions of the arrival of the acoustic wave to the measuring point in the form of an acoustic map superimposed on the photographic image of the object under study.

An acoustic camera by GFAI with a microphone matrix comprising 48 microphones located over a surface with a diameter of $3.4 \mathrm{~m}$ was applied for the purposes of these measurements. The range of the dynamic characteristics of the noise measured by the camera was from 35 to $130 \mathrm{~dB}$, and the frequency range from $100 \mathrm{~Hz}$ to $13 \mathrm{kHz}$. For the study of noise emitted from a wind turbine, a star matrix was used, which is dedicated to measurements from a long distance ranging from 7 to $500 \mathrm{~m}$. The measurement was made at a point $200 \mathrm{~m}$ from the T5 turbine, and the matrix was placed $1.5 \mathrm{~m}$ above the ground. The measurement results in the form of an acoustic photo are presented in Figure 19.

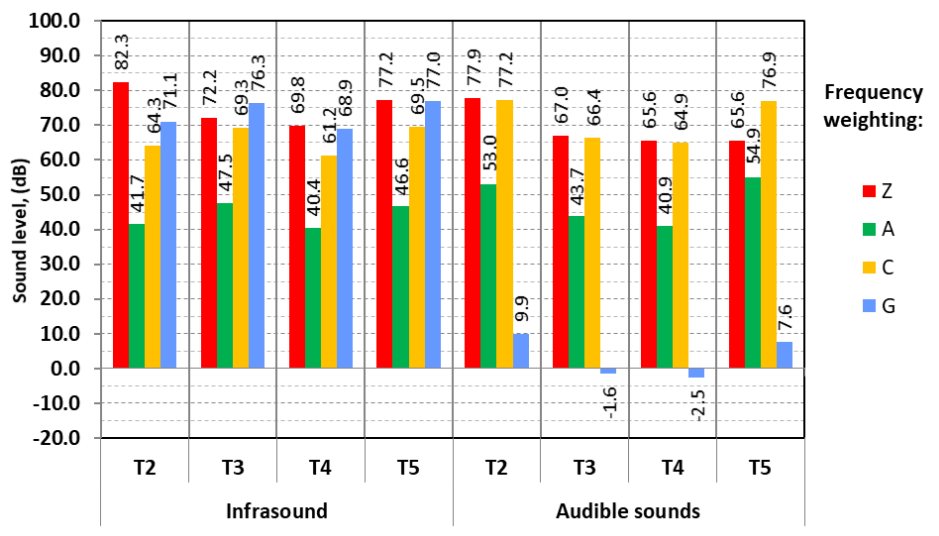

Figure 18. Comparison of equivalent noise levels weighted by various curves in the infrasound and audible band.

Figure 20 shows the view of an acoustic camera that tests the noise of a wind turbine. In the presented acoustic photo, two sources of the sound wave can be clearly indicated. The first is a wind turbine nacelle, which contains mechanical parts responsible for the production and conversion of the kinetic energy of the wind into electricity. At the observation site, the noise level from these devices was about $42.0 \mathrm{~dB}$. The second place of emission is associated with turbulence and sweeping air resulting from the blade passage near the 
wind turbine tower. At the place of observation, the noise level from the aerodynamic phenomena occurring during the rotation of the rotor is approx. $42.6 \mathrm{~dB}$.

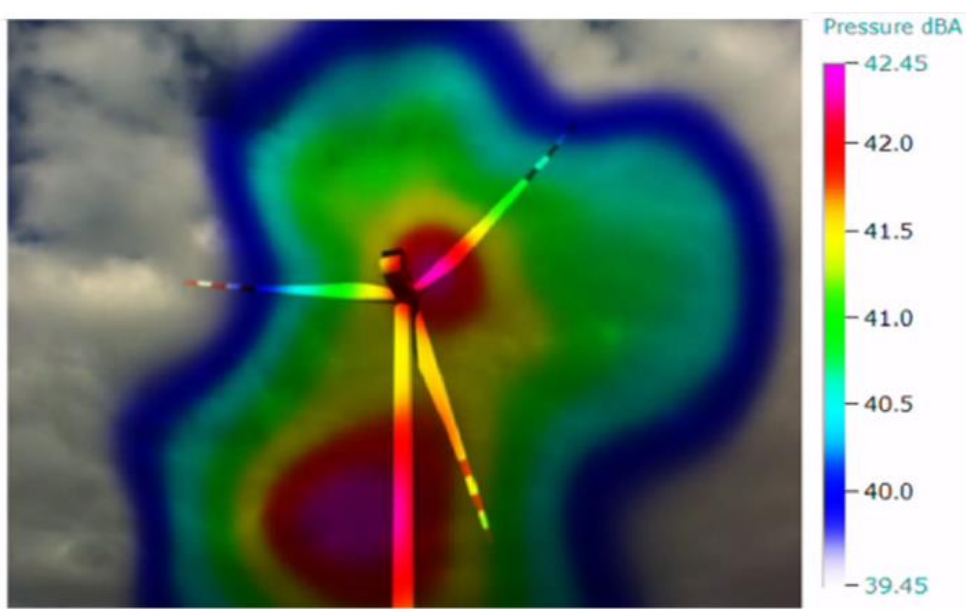

Figure 19. Acoustic photo illustrating the location of the occurrence of acoustic wave during operation of wind turbine [7].

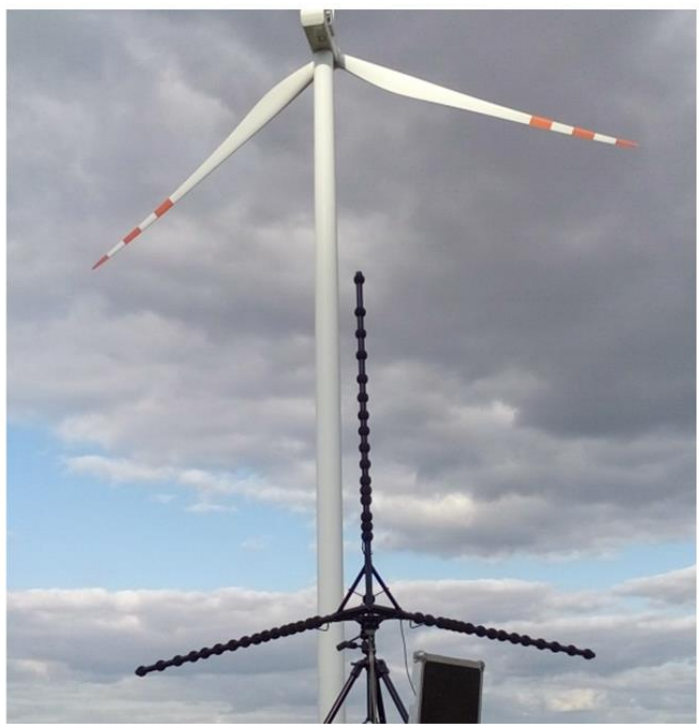

Figure 20. Image of acoustic camera during measurements [7].

\subsection{Evaluation of the Results in Terms of Legal Criteria Values}

In Poland, the issues related to infrasound noise in the ambient environment are not controlled by any legal regulations. At present, the only law that relates to the issue of infrasound noise is the regulation of the minister of labor and social policy on occupational safety and health, which refers to the norms and implementing regulations in this regard. Currently, there are no executive regulations regulating the issues of infrasound noise. The only legal documents in Poland that regulate the issues related to infrasound noise include the PN-Z-01338, PN-ISO 9612 and PN-ISO 7196 standards. According to the PN-Z01338:2010 standard, the equivalent sound pressure level corrected by the $G$ frequency characteristic, related to an $8 \mathrm{~h}$ working day should not exceed $102 \mathrm{~dB}$, and in the case of performing conceptual work that requires particular mental focus, this is $86 \mathrm{~dB}$.

On the basis of the obtained measurement results, we can conclude that the levels of generated infrasound signals for the tested wind turbines were significantly below the criteria-based values specified in the standard. A summary of the measured equivalent sound levels of the weighted G-curve of the tested turbines with the marking of the 
permissible levels is presented in Figure 21. Considering the fact that the measured levels were recorded in the immediate vicinity of the tested turbines, the level of the noise weighted by the G-curve at a distance of several hundred meters, where the residential buildings were located, would reach even lower levels, provided that an appropriate distance from traffic noise sources is maintained.

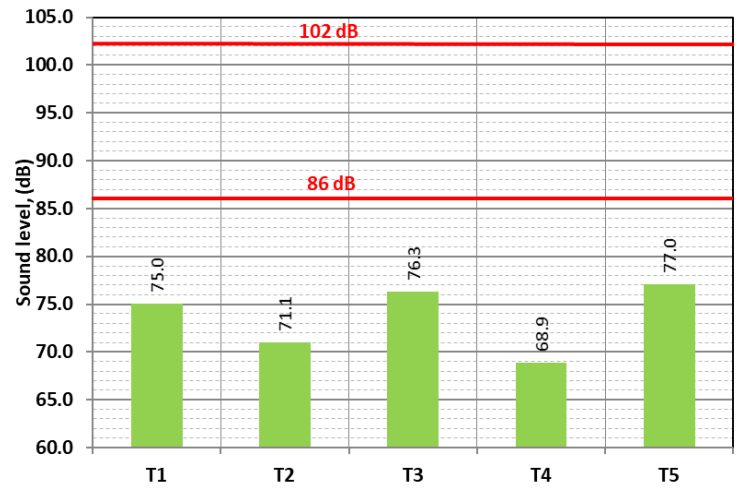

Figure 21. Equivalent noise levels weighted by the $\mathrm{G}$ curve recorded at the tested turbines T1, T2, T3, T4 and T5 along with the permissible levels of infrasound noise in the working environment specified in the PN-Z-01338 standard.

In addition to the limit levels defined in the standard, there are also recommendations set out in the work of Mirowska [27], which define criteria based on hearing thresholds. As part of the evaluation, the evaluation curves presented in the table were compared with the measured spectral noise level distribution. This summary is presented in Figure 22.
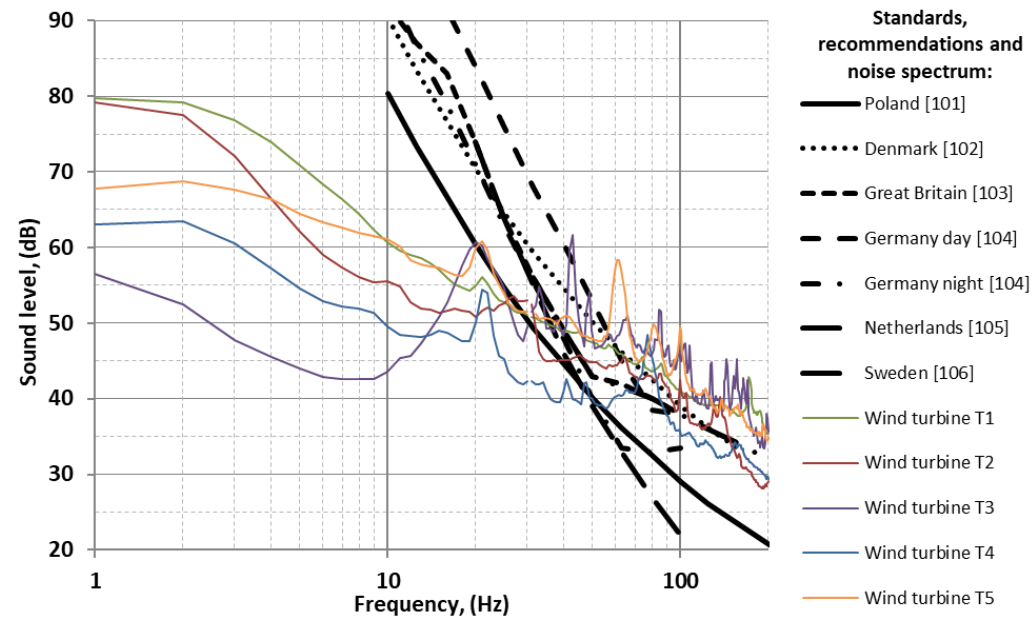

Figure 22. Comparison of amplitude spectra of investigated wind turbines from various countries. Results of study based on details in [28].

On the basis of the dependencies developed in this study, we can conclude that in the infrasound range i.e., below $20 \mathrm{~Hz}$, none of the tested turbines exceeded the reference values. Only in the low frequency band, above $30 \mathrm{~Hz}$, do the recorded spectra have values higher than the reference values. In the case of the Polish curve, the higher the frequency, the greater the level of exceeded results, reaching up to $25 \mathrm{~dB}$ for the $\mathrm{T} 3$ turbine, at which a large ratio of the noise spectrum was related to traffic on nearby roads. This fact only proves that the noise of the tested turbines at the measurement spot assumes a level that is perceived by humans for frequencies above $30 \mathrm{~Hz}$. For longer distances, in the order of several hundred meters, the measured values would be below or close to the reference values in the standard. To sum up, the sound pressure level of infrasound signals emitted by the operation of the tested high-power wind turbines, regardless of the wind speed, 
weather conditions, design solutions, operation time, rated power value and the amount of electric power delivered to the power system, does not exceed the criteria specified in the applicable legal regulations on assessment of infrasound noise in the working environment. Meeting the standards at workplaces, defined for the environment where people are directly at the source and exposed to higher exposure values, guarantees no nuisance noise levels in residential areas surrounded by wind turbines, usually located several hundred meters from the turbines.

\section{Conclusions}

The following conclusion can be stated on the basis of the measurements and analysis conducted in this study:

- The levels of infrasound measured in the immediate vicinity of the tested high-power wind turbines do not exceed the criteria-based levels specified for the assessment of infrasound noise for the working environment.

- The best descriptive measure for assessing the noise of wind turbines in terms of infrasound frequencies is associated with the use of the weighted G-curve noise level.

- Measurement at the point where the acoustic power level should be derived in accordance with the PN EN 61400-11 standard can be extended to include the range of infrasound frequencies, and the measurement result can be given as one of the parameters of the turbine's performance.

- In order to exclude the influence of factors other than wind speed on the measurement results obtained, it is necessary to measure other parameters that define weather conditions, i.e., air temperature and humidity, as well as the level of precipitation.

- For the purposes of conducting a detailed assessment of the impact of infrasound signals it is necessary to determine the spectral distributions of the noise level with a resolution of at least one third (preferably $1 \mathrm{~Hz}$ ), as well as calculate the difference between the sound level weighted by the $\mathrm{A}$ and $\mathrm{C}$ curve in order to determine the occurrence of low-frequency component.

- All the determined waveforms of amplitude spectra for the measured infrasound signals emitted by the tested wind turbines assumed the maximum value of the sound pressure level in the range of the lowest frequencies (i.e., in the range of 1-5 Hz), and the shape of their waveforms were characterized by similar characteristics in terms of decreasing level values sound pressure with an increase in frequency and the occurrence of harmonic components in the calculated spectra, for which local increases of the measured values occur.

- In order to eliminate disturbances caused by other sources of infrasound noise, such as transport routes (cars, trains) located in the vicinity of the tested turbines, as well as the operation of agricultural machinery and vehicles, it is advisable to conduct tests during the periods of their lowest activity (e.g., during the night).

- The results of the comparative analysis of the noise level in the infrasound and audible range demonstrate that the acoustic energy mainly includes the range of low and infrasound frequencies, and the measured levels significantly depend on the weighting curves.

- The values of the acoustic pressure level of infrasound signals recorded for the tested wind turbines depend on the wind velocity, temperature and humidity.

- Regardless of the investigated influence of defined parameters and external factors, the values of the recorded levels of infrasound noise did not exceed $80 \mathrm{~dB}$ weighted by the G-curve and were below the reference values specified for the working environment, which confirms the assumed research thesis.

Author Contributions: Conceptualization, T.M. and T.B.; methodology, T.M. and D.W.; validation, T.M., T.B., D.W. and M.K.; formal analysis, T.M., D.W. and M.K.; investigation, T.M., T.B.; resources, T.M. and T.B.; writing—original draft preparation, T.M. and D.W.; writing—review and editing, M.K.; 
visualization, T.M., D.W. and M.K.; supervision, T.B.; project administration, T.B.; funding acquisition, T.B. All authors have read and agreed to the published version of the manuscript.

Funding: This research was co-financed by the National Science Centre, Poland (NCN) as a part of the OPUS Research Project No. 2015/17/B/ST8/03371.

Conflicts of Interest: The authors declare no conflict of interest.

\section{References}

1. Harrison, J.P. Wind Turbine Noise. Bull. Sci. Technol. Soc. 2011, 31, 256-261. [CrossRef]

2. Inagaki, T.; Li, Y.; Nishi, Y. Analysis of aerodynamic sound noise generated by a large-scaled wind turbine and its physiological evaluation. Int. J. Environ. Sci. Technol. 2015, 12, 1933-1944. [CrossRef]

3. Zagubien, A.; Wolniewicz, K. The impact of supporting tower on wind turbine noise emission. Appl. Acoust. 2019, 155, 260-270. [CrossRef]

4. Tachibana, H.; Yano, H.; Fukushima, A.; Sueoka, S. Nationwide field measurements of wind turbine noise in Japan. Noise Control Eng. J. 2014, 62, 90-101. [CrossRef]

5. Tonin, R. A Review of Wind Turbine-Generated Infrasound: Source, Measurement and Effect on Health. Acoust. Aust. 2018, 46, 69-86. [CrossRef]

6. Malec, T.; Boczar, T.; Wotzka, D.; Fracz, P. Comparison of low frequency signals emitted by wind turbines of two different generator types. E3S Web Conf. 2017, 19, 01001. [CrossRef]

7. Malec, T. Pomiary i Analiza Sygnałów Infradźwiękowych Generowanych Praca Turbin Wiatrowych Dużych Mocy (Measurement and Analysis of Infrasonic Signals Generated by Operation of High Power Wind Turbines). Ph.D. Thesis, Politechnika Opolska, Opole, Poland, 2016.

8. Zajamšek, B.; Hansen, K.L.; Doolan, C.J.; Hansen, C.H. Characterisation of wind farm infrasound and low-frequency noise. J. Sound Vib. 2016, 370, 176-190. [CrossRef]

9. Hansen, C.; Zajamšek, B.; Hansen, K. Infrasound and Low-Frequency Noise from Wind Turbines. In Fluid-Structure-Sound Interactions and Control. Lecture Notes in Mechanical Engineering; Zhou, Y., Lucey, A., Liu, Y., Huang, L., Eds.; Springer: Berlin/Heidelberg, Germany, 2016; pp. 3-16. ISBN 9783662488669.

10. O'Neal, R.D.; Hellweg, R.D.; Lampeter, R.M. Low frequency noise and infrasound from wind turbines. Noise Control Eng. J. 2011, 59, 135. [CrossRef]

11. Pilger, C.; Ceranna, L. The influence of periodic wind turbine noise on infrasound array measurements. J. Sound Vib. 2017, 388, 188-200. [CrossRef]

12. Lv, J.; Yang, W.; Zhang, H.; Liao, D.; Ren, Z.; Chen, Q. A Feasibility Study to Reduce Infrasound Emissions from Existing Wind Turbine Blades Using a Biomimetic Technique. Energies 2021, 14, 4923. [CrossRef]

13. Keith, S.E.; Daigle, G.A.; Stinson, M.R. Wind turbine low frequency and infrasound propagation and sound pressure level calculations at dwellings. J. Acoust. Soc. Am. 2018, 144, 981-996. [CrossRef] [PubMed]

14. ISO 7196:1995 Acoustics_Frequency-Weighting Characteristic for Infrasound Measurements. 1995, p. 6. Available online: https: / / www.iso.org/standard/13813.html (accessed on 20 August 2021).

15. ISO 9612:1997 Acoustics-Guidelines for the Measurement and Assessment of Exposure to Noise in a Working Environment. 1997, p. 25. Available online: https://www.iso.org/standard/17425.html (accessed on 20 August 2021).

16. PN-Z-01338:2010 Akustyka-Pomiar i Ocena Hałasu Infradźwiękowego na Stanowiskach Pracy. 2010, p. 8. Available online: https: / /sklep.pkn.pl/pn-z-01338-2010p.html (accessed on 20 August 2021). (In Polish).

17. PN-EN 61400-11:2013-07 Wind Turbines-Part 11: Acoustic Noise Measurement Techniques. 2013, p. 68. Available online: https://standards.iteh.ai/catalog/standards/clc/951314b8-8d7b-4224-b62d-4a5e17f7e04f/en-61400-11-2013 (accessed on 20 August 2021).

18. McCunney, R.J.; Mundt, K.A.; Colby, W.D.; Dobie, R.; Kaliski, K.; Blais, M. Wind turbines and health: A critical review of the scientific literature. J. Occup. Environ. Med. 2014, 56, e108-e130. [CrossRef] [PubMed]

19. Kurpas, D.; Mroczek, B.; Karakiewicz, B.; Kassolik, K.; Andrzejewski, W. Health impact of wind farms. Ann. Agric. Environ. Med. 2013, 20, 595-604. [PubMed]

20. Berger, R.G.; Ashtiani, P.; Ollson, C.A.; Whitfield Aslund, M.; McCallum, L.C.; Leventhall, G.; Knopper, L.D. Health-Based Audible Noise Guidelines Account for Infrasound and Low-Frequency Noise Produced by Wind Turbines. Front. Public Health 2015, 3, 31. [CrossRef] [PubMed]

21. Knopper, L.D.; Ollson, C.A. Health effects and wind turbines: A review of the literature. Environ. Health 2011, 10, 78. [CrossRef] [PubMed]

22. Malec, T.; Boczar, T. Analysis of infrasound noise emitted by high-power wind turbine with synchronous generator. In Proceedings of the 2013 12th International Conference on Environment and Electrical Engineering, Wroclaw, Poland, 5-8 May 2013; pp. 400-405.

23. Pierzga, R.; Boczar, T.; Wotzka, D.; Zmarzły, D. Studies on Infrasound Noise Generated by Operation of Low-Power Wind Turbine. Acta Phys. Pol. A 2013, 124, 542-545. [CrossRef] 
24. Wotzka, D.; Boczar, T.; Malec, T.; Pierzga, R. Analysis of Vibro-Acoustic Signals Generated during Operation of Micro Wind Turbines. Acta Phys. Pol. A 2013, 124, 595-597. [CrossRef]

25. Boczar, T.; Malec, T.; Wotzka, D. Studies on Infrasound Noise Emitted by Wind Turbines of Large Power. Acta Phys. Pol. A 2012, 122, 850-853. [CrossRef]

26. IEC 61672-1:2003 Electroacoustics—Sound Level Meters_Part 1: Specifications. 2012, p. 103. Available online: https://standards.iteh. ai/catalog/standards/clc/0edd9b4a-ab53-4fa9-a42a-8d0cfc9d59c4/en-61672-1-2003 (accessed on 20 August 2021).

27. Mirowska, M. An Investigation and Assessment of Annoyance of Low Frequency Noise in Dwellings. Noise Notes 2002, 1, 30-34. [CrossRef]

28. Pawlas, K. Wpływ infradźwięków i hałasu o niskich częstotliwościach na człowieka—przegląd piśmiennictwa. Pod. Metod. Oceny Sr. Pr. 2009, 2, 27-64. 